\title{
Enhanced External Counterpulsation in Patients with Advanced Ischemic Cardiomyopathy
}

\author{
B. Przywara-Chowaniec ${ }^{a}$, M. Gawlikowski ${ }^{b}$, A. Kuczaj $^{a}$, M. Bachorz $^{c}$, \\ P. Czechowski ${ }^{c}$, P. Kowalski ${ }^{c}$, M. Geodecki ${ }^{c}$, D. Kawecki ${ }^{a}$, K. Barańska ${ }^{a}$, \\ M. Paluch ${ }^{a}$, M. PluszczyK $^{a}$, M. Opara $^{a}$, A. Puzio ${ }^{a}$ And E. Nowalany-Kozielska ${ }^{a}$ \\ ${ }^{a}$ Silesian Medical University in Katowice, 2nd Department 1st Clinical Ward of Cardiology in Zabrze, Poland \\ ${ }^{b}$ Foundation of Cardiac Surgery Development, Zabrze, Poland \\ ${ }^{c}$ Institute of Medical Technology and Equipment, Zabrze, Poland \\ A significant increase in the number of patients with heart failure of varied etiology has been observed in \\ the recent years. Apart from pharmacological and surgical therapies, new, non-invasive assistance methods of \\ cardiovascular system are still sought. One of them is external counterpulsation. Within this study, effectiveness \\ of such a form of therapy has been examined in a group of 10 patients with an ischemic left ventricular systolic \\ dysfunction. It has been shown that external counterpulsation has a beneficial influence onto the result of a \\ six-minute walk test and causes a slight decrease in the creatinine concentration in the patients undergoing the tests.
}

PACS: 47.63.Ec, 82.60.Fa

\section{Introduction}

Enhanced external counterpulsation (EECP) is a new, non-invasive form of therapy used in patients with cardiac failure of varied etiology [1-3]. The idea of EECP is a modification of a widely clinically used invasive counterpulsation method with intraaortic balloon (IABP) $[4,5]$, where a polyethylene balloon of flexible walls is introduced into the aorta via the femoral artery. The balloon is cyclically filled with gas (usually helium, minimizing the creation of an air-embolism in the case of a break) and the diastole of the balloon is synchronized with the systole of the heart muscle. The filling of the balloon during a systole of the heart causes a part of blood to be transferred from the aorta to the coronary arteries. A synchronization of the balloon action with the moment of left ventricle systole is achieved by detection of the $R$ wave in the QRS complex or, in modern solutions, by measurement and analysis of blood pressure wave in the aorta with the use of a fibre-optic sensor [6-10]. The synchronization itself constitutes a part of the significant problem of automation of mechanical heart supporting process [10-15].

Unlike intraaortic counterpulsation, the external counterpulsation is a completely non-invasive method consisting in a cyclical pressing of lower limbs with the use of pneumatic cuffs (Fig. 1). The cuffs are located around calves, thighs and buttocks. Compressed air is transferred to the subsequent cuffs causing their systole and pressure of the chosen areas of the limbs. As a result of a sequential filling of the individual cuffs with air, a transfer of blood happens from the well supplied with blood big parts of muscles of lower limbs in the direction of the heart. The systole of the cuffs is synchronized with the systole of the heart muscle. It has been proven $[1-3,6]$ that the following are an effect of the described system of external counterpulsation:
- an increase in the diastolic pressure of left ventricle filling,

- decrease in the systemic resistance and increase in venous return,

- lowering of afterload,

- improvement in perfusion of coronary vessels and systemic organs.

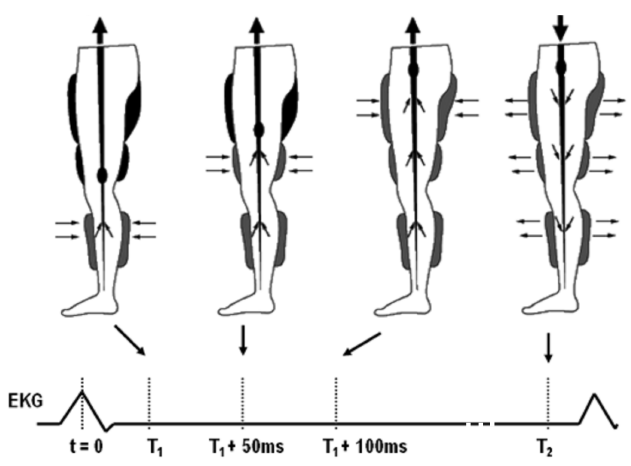

Fig. 1. Principle of external counterpulsation action.

One of the best recognized mechanisms of therapeutic action of external counterpulsation is an improvement in perfusion resulting from an increase of diastolic pressure [6]. The other mechanisms of the EECP beneficial action onto blood circulation, such as: opening or creation of collateral circulation, changes in the function of endothelium cells or changes in the concentration of natriuretic factors are not fully understood or explained.

In order to achieve the expected therapeutic effect, the pressure of air filling the collars must be higher than the 
systolic blood pressure and the process of applying pressure to the individual parts of lower limbs must be synchronized with the patient's heart rhythm. The scope of air pressure in the cuffs is from 90 to $300 \mathrm{mmHg}$. The treatment of external counterpulsation is performed under a permanent pletysmographic control (enabling an as- sessment of blood flow changes in collateral vessels close to body surface), electrocardiogram and the values of arterial blood saturation measured with a non-invasive pulseoximetric sensor put on the patient's finger. The recommendations and contraindications for EECP have been presented in Table I [2, 3, 7].

Recommendations and contraindications for EECP therapy.

TABLE I

\begin{tabular}{|c|c|}
\hline Recommendations & Contraindications \\
\hline $\begin{array}{l}\text { - patients with angina pectoris not responding } \\
\text { to pharmacotherapy, limiting their activity in } \\
\text { order to avoid effects of the angina } \\
\text { - patients who do not want to undergo an inva- } \\
\text { sive operation of revascularization } \\
\text { - decreased systolic function of left ventricle } \\
\text { EF < 35\% } \\
\text { - co-existence of diseases that increase surgery- } \\
\text { associated risks (diabetes, renal insufficiency, } \\
\text { lung diseases) } \\
\text { - patients disqualified from invasive revascular- } \\
\text { ization } \\
\text { - patients with small-vessel disease } \\
\text { - elderly patients with a higher risk of disorders }\end{array}$ & $\begin{array}{l}\text { - arrhythmias disturbing the action of the assist- } \\
\text { ing apparatus } \\
\text { - hemophilia } \\
\text { - thrombophlebitis } \\
\text { - acute arterial obstruction of lower limbs } \\
\text { - proven aortic aneurysm requiring surgical in- } \\
\text { tervention } \\
\text { - pregnancy } \\
\text { - moderate or acute aortic regurgitation } \\
\text { - blood pressure exceeding } 180 \text { mmHg } \\
\text { - medical history of pulmonary embolism } \\
\text { - acute chronic obstructive pulmonary disease } \\
\text { (COPD) }\end{array}$ \\
\hline
\end{tabular}

\section{Aim of the study}

The aim of the research was an initial assessment of a therapeutic action of external counterpulsation in patients with left ventricular dysfunction.

\section{Material and methodology of examinations}

The examinations were carried out on a group of ten patients (men, age $66 \pm 7$ years) with diagnosed significant ischemic left ventricular systolic dysfunction (LVSD). Assessment was given to chosen biochemical (creatinine, sodium and B-type natriuretic peptide NTproBNP [16] concentration in the blood) and functional (the six-minute walk distance) parameters in patients before and after treatment of external counterpulsation. Each patient was given 35, one-hour long treatments.

A prototype apparatus, ECP-100 constructed by ITAM [7], was used in the examinations. It is made of: a central unit (computer controlling contractions of the cuffs), an ECG module with on-skin electrodes, pulseoximeter and cuffs put around the patient's calves, thighs and buttocks. During the treatment, the air pressure in the cuffs was $90-200 \mathrm{mmHg}$.

The cardiac function was assessed by means of the six-minute walk test and measurements of the sodium concentration in the blood. The function of the kidney was monitored by measurements of the concentration of creatinine in the blood. Before the counterpulsation, every patient was assessed from the point of view of the six-minute walk distance - 6MWT. During this examination the patients were not given oxygen nor medicines by continuous infusion. Also the level of creatinine, sodium and natriuretic peptide in blood were assessed. The same parameters were given analysis after the completed cycle of treatments. The six-minute walk test was applied to assess the cardiac function.

Due to the small number of tests, the unknown distribution of a random variable in population and group connection, assessment of statistical results characteristics of the measured parameters before and after the application of external counterpulsation has been done with Wilcoxon signed-rank test [8] at the level of significance $p=0.05$. The following hypotheses have been made:

$\mathrm{H} 0$ : the median of the difference of measured parameters before and after application of EECP is zero;

$\mathrm{H} 1$ : the median of the difference of measured parameters before and after application of EECP is other than zero.

Calculations have been done with Statistica software.

\section{Results}

During EECP therapy the following signals were monitored: pletysmogram, ECG and pressures in the cuffs. The demonstration course of the treatment has been presented in Fig. 2. 


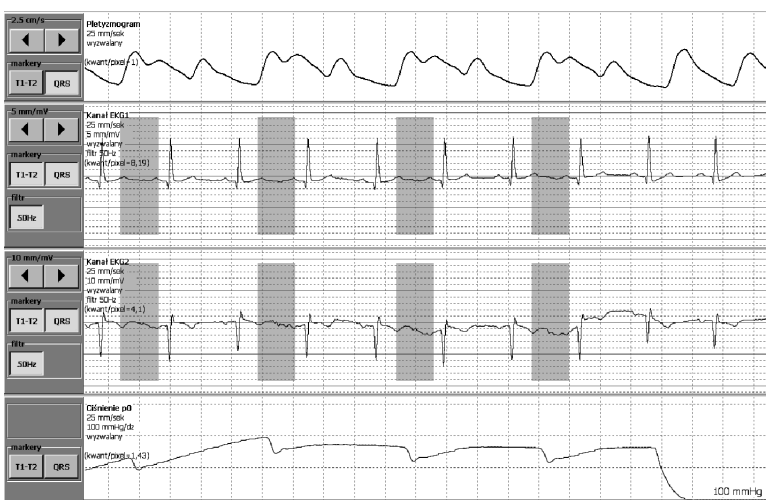

Fig. 2. Course of the EECP therapy (from above): pletysmogram, ECG (lead I), ECG (lead III), pressure wave in the cuff.

During the treatments applied so far, none of the patients undergoing EECP therapy had complications observed. The characteristics of the examined group has been presented in Table II. The comparison of medium values of the measured parameters and their standard deviations in patients before and after the application of EECP has been presented in Table III.

TABLE II

Characteristics of examined group - summary.

\begin{tabular}{l|c}
\hline \hline number of examined patients & 10 \\
age of patients [years] & $66 \pm 7$ \\
number of ECP [n] & 35 \\
patient's average total time of treatment [min] & $1997 \pm 100$
\end{tabular}

The statistical analysis of the measured parameters revealed (Fig. 3), that the H0 hypothesis may be dismissed for the $6 \mathrm{~min}$ walk test $(p=0.0179)$ and concentration of natriuretic peptide $(p=0.0464)$ but there are no statistical proof to reject this hypothesis for creatinine $(p=0.6858)$ and sodium $(p=0.6749)$ measurements at the level of significance $p=0.05$ (cf. Table III, the $p$ value).

Comparison of values of measured parameters and the result of statistical test

TABLE III before and after application of EECP therapy.

\begin{tabular}{|c|c|c|c|c|c|}
\hline \multirow[b]{2}{*}{ Parameter } & \multicolumn{2}{|c|}{ Before EECP } & \multicolumn{2}{|c|}{ After EECP } & \multirow[b]{2}{*}{$p$} \\
\hline & median & $\begin{array}{c}\text { quartile } \\
25 \% / 75 \%\end{array}$ & median & $\begin{array}{c}\text { quartile } \\
25 \% / 75 \%\end{array}$ & \\
\hline distance of the 6 min walk test $[\mathrm{m}]$ & 435 & $359 / 465$ & 495 & $415 / 504$ & 0.0179 \\
\hline creatinine $[\mu \mathrm{mol} / 1]$ & 87.9 & $84.1 / 96.0$ & 79.0 & $72.6 / 90.0$ & 0.6858 \\
\hline sodium $[\mathrm{mmol} / \mathrm{l}]$ & 135 & $134 / 138$ & 138 & $135 / 140$ & 0.6749 \\
\hline NTproBNP [pg/ml] & 417.0 & $346.0 / 488.6$ & 229.6 & $178.2 / 273.3$ & 0.0464 \\
\hline
\end{tabular}

\section{Discussion}

The treatment of external counterpulsation is performed under pletysmographic recording control. The therapeutic increase of diastolic pressure causes an increase in the perfusion pressure in epicardial coronary arteries and cardiac perfusion [2]. The mechanisms of a beneficial effect of external counterpulsation are discovered anew in clinical practice. Applebaum et al. [6] proved that a sequential external counterpulsation increases cerebral blood flow and renal circulation. In our study the influence of EECP therapy on the blood pressure wave has been unambiguously pointed out: the comparison of the pulse waves of the patient without and during supporting has been presented in Fig. 5 (the measurements were carried out by means of non-invasive, pulseoxymetric sensor, therefore the vertical scales of the charts were not presented).

In the group of patients, with significant ischemic left ventricular systolic dysfunction, under our assessment, the following parameters improved: the distance of the 6 min walk test and the level of natriuretic peptide (cf. Fig. 4 and Table III). Moreover, the value of creatinine slightly decreased and the $\mathrm{Na}$ concentration did not significantly change. The testing of statistic hypothesis revealed the presence of statistically significant differences between medians of results of the 6 min walk test and the concentration of NTproBNP before and after treatment by means of EECP. The improvement of those parameters indicates on the effectiveness of EECP therapy. It is most probable that the improvement in blood supply to kidneys after the treatment caused this beneficial hemodynamic effect.

Literature shows vast evidence of an improvement in physical function. The multicenter study of enhanced external counterpulsation (MUST-EECP) examination, randomized, controlled placebo with a double-blind test assessed the effectivity of EECP in patients with ischemic heart disease and symptoms of angina not undergoing standard treatment. It was proven that external counterpulsation decreases the symptoms of angina and extends the time to the strain reduction of ST segment (the section of ECG between the $\mathrm{S}$ and $\mathrm{T}$ waves, corresponded to the myocardial repolarization) in patients with symptomatic coronary disease [9]. 


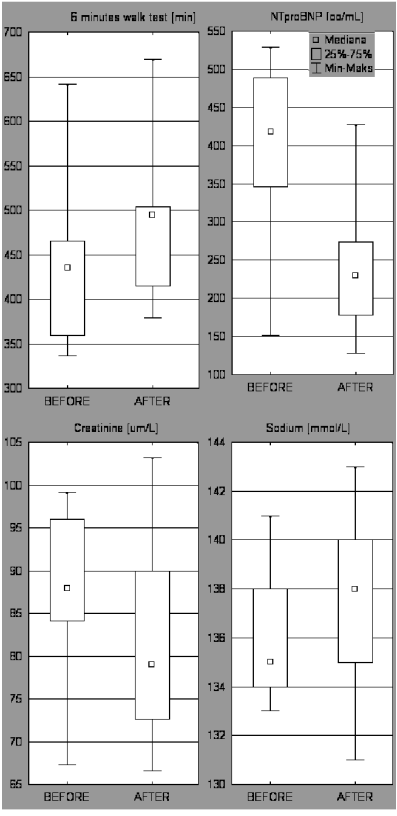

Fig. 3. The results of statistical analysis: medians, quartiles and range of data for analyzed probe.

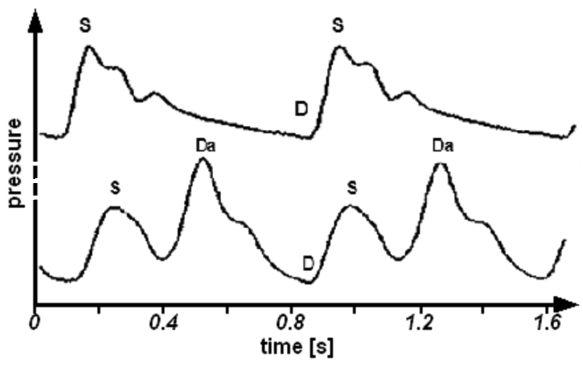

Fig. 4. Pulse pressure waves of the patient without (top) and during (bottom) EECP therapy (S - systolic pressure, D - diastolic pressure, $\mathrm{Da}$ - intensification of diastolic pressure caused by EECP therapy).

The test of six-minute walk (6MWT) is a safe test, easy to carry out and well tolerated by patients in comparison with other strain tests. The distance measured during the 6 min walk is usually completed with a measurement of blood oxygenation of arterialized capillary blood before and after the test with the use of a pulseoximeter $\left(\mathrm{SpO}_{2}\right)$ as well as with a non-invasive measurement of blood pressure. During this test, the patients should make, within 6 min, a certain distance on a flat area "at their own pace". Guidelines do not recommend a conveyor track nor tracks of circular shape.

In patients given the treatment of counterpulsation, an increase in the $6 \mathrm{~min}$ walk distance was stated from $437 \mathrm{~m}$ to $490 \mathrm{~m}$. An increase of strain tolerance assessed with the $6 \mathrm{~min}$ walk may significantly improve quality of life for patients with ischemic left ventricular systolic dysfunction.

\section{Conclusions}

1. External counterpulsation seems to be a safe and effective method of treatment, and assisting pharmacotherapy, for patients with ischemic left ventricular systolic dysfunction.

2. Counterpulsation is beneficial for the improvement of the functioning of kidneys in patients with cardiovascular insufficiency.

3. Treatments of external counterpulsation improve physical function assessed by 6 min walk test.

\section{References}

[1] B. Przywara-Chowaniec, A. Kuczaj, P. Starosta, E. Nowalany-Kozielska, Nationwide Medical Review 3, 36 (2011) (in Polish).

[2] A. Milewska, H. Wysocki, Folia Cardiologica Excerpta 11, 407 (2004) (in Polish).

[3] R. Zaczek, G. Opolski, Kardiologia po Dyplomie 7, 29 (2008) (in Polish).

[4] M. Krishna, K. Zacharowski, Critical Care Pain 9, 24 (2009).

[5] J.J. Schreuder, A. Castiglioni, A. Donelli, F. Maisano, J. Jansen, R. Hanania, P. Hanlon, J. Bovelander, O. Alfieri, Ann. Thoracic Surg. 79, 1017 (2005).

[6] R.M. Apfelbaum, R. Kasliwal, P. Tunick, N. Konecky, W. Katz, N. Trehan, I. Kronzon, Am. Heart J. 133, 611 (1997).

[7] M. Bachorz, M. Geodecki, M. Darowski, M. Kozarski, Acta Bio-Optica Inform. Med. 15, 52 (2009) (in Polish).

[8] A. Stanisz, Biostatistics, Jagiellonian University Publishing House, Cracow 2005.

[9] R.R. Arora, T.M. Chou, D. Jain, B. Fleishman, L. Crawford, T. McKiernan, R. Nesto J. Am. College Cardiol. 33, 1833 (1999).

[10] T. Pustelny, I. Zielonka, C. Tyszkiewicz, P. Karasinski, B. Pustelny, Opto-Electron. Rev. 14, 161 (2006).

[11] M. Gawlikowski, T. Pustelny, R. Kustosz, Europ. Phys. J. Spec. Top. 154, 71 (2008).

[12] M. Gawlikowski, T. Pustelny, R. Kustosz, Europ. Phys. J. Spec. Top. 154, 65 (2008).

[13] J. Ignac-Nowicka, T. Pustelny, Z. Opilski, E. Maciak, W. Jakubik, M. Urbanczyk, Optical Eng. 42, 2978 (2003).

[14] M. Gawlikowski, T. Pustelny, R. Kustosz, J. Phys. IV: JP (France) 137, 73 (2006).

[15] S. Muc, T. Gudra, E. Bereś-Pawlik, Acta Phys. Pol. A 120, 702 (2011).

[16] M. Grabowski, K.J. Filipiak, Diseases Heart Blood Vessels 3, 106 (2006) (in Polish). 